\title{
Aspergillus Fumigatus Complex
}

National Cancer Institute

\section{Source}

National Cancer Institute. Aspergillus Fumigatus Complex. NCI Thesaurus. Code

C122245.

A non-taxanomic grouping of bacteria that have been assigned to the Aspergillus genus and are morphologically and physiologically similar to Aspergillus fumigatus. 